\title{
Community Preceptors' Views of a Required Third-Year Family Medicine Clerkship
}

\author{
Donald O. Kollisch, MD; Pamela York Frasier, MSPH; Lisa Slatt, MEd; Marie Storaasli, MS
}

Background: Previous studies documented the impor-

tance of family medicine clerkships to medical student education and to the potential costs of precepting students borne by community physicians. But what are the physicians' views of their experience, their perceived needs for teaching, and sources of satisfaction from the preceptor role?

Objectives: To explore preceptors' views of a required, third-year family medicine clerkship, focusing on satisfaction with the teaching experience, effect of having students in the practice, and concerns about continuing as a preceptor.

Methods: Preceptors from 38 private practices were asked to participate in a 15-minute telephone survey, using a semistructured interview format.

Resulłs: Thirty-five physicians (92\%) agreed to participate and 33 of the 35 primary preceptors were interviewed. Of those interviewed, $29(88 \%)$ indicated a positive teaching experience, and 31 (94\%) desired to continue precepting. Intangible rewards (eg, love of teaching or "giving back" to the specialty of family medicine) far outweighed tangible rewards (eg, dinners or letters of appreciation) with regard to their desire to precept. Continued satisfaction with precepting seemed to be affected by loss of revenue to the practice, longer work hours, ability to effectively manage time and patient load, and need for additional educational resources and equipment.

Conelusions: Intrinsic rewards seem to be a key factor in the physicians' decision to precept. Moreover, to reinforce the preceptor's continued desire to precept, faculty development, provision of educational tools and resources, and remuneration may be necessary. Preceptors should be asked routinely about their needs, and special programs of support should be offered.

Arch Fam Med. 1997;6:25-28

Editor's Note: This is for all of the family physicians thinking about participating in student education by providing education to thirdyear clerkship students. The bottom line: these physicians (albeit self-selected volunteers) believed teaching was worth it. It is also for those responsible for the training to make it as smooth as possible. Training in family physician offices exposes students to what medicine is all about! Our medical school is grateful to the many family physicians who make our students' education a truly excellent, memorable one. For those of you who precept students, thank you! For those of you who might be interested in precepting, call your favorite medical school. The experience is worth it! Thank you!

Marjorie A. Bowman, MD, MPA

From the Department of Family Medicine (Dr Kollisch and Mss Frasier and Slatt) and the School of Education (Ms Storaasli), University of North Carolina, Chapel Hill. Dr Kollisch is now with the Department of Community and Family Medicine, Dartmouth Medical School, Hanover, $\mathrm{NH}$

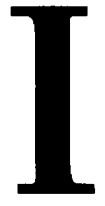

NCREASED TRAINING of medical students in outpatient, community-based practices requires critical collaboration with, and cooperation from, private practitioners who have chosen patient care, rather than teaching, as a career. Strategies to keep physicians satisfied with their precepting role are gaining attention.

Studies have examined costs and rewards associated with teaching students in private offices. Pawlson et $a^{1}$ estimated a cost of about $\$ 50$ per studentday for a typical clerkship student in a fee- for-service practice. Costs included decreased physician productivity and increased time spent in teaching. Vinson and Paden $^{2}$ reported that preceptors in private practice increased their work day by an average of 46 minutes when students were in their offices. Garg et $\mathrm{al}^{3}$ estimated a reduction in productivity as much as $30 \%$ to $40 \%$ for physicians who were teaching in a community health center. Rewards associated with teaching included continuing education activities and intellectual stimulation. Chambliss ${ }^{4}$ reported that preceptors believed education activities offered by the university and directed toward students assigned to their practice also would be available to the physicians and their staff. In the recent study by Usatine et $\mathrm{al},{ }^{5}$ preceptors seemed to receive positive rewards from interaction with preclinical students, although the students offered limited help in the practice. ${ }^{5}$ Recently, researchers also have investigated types of support needed by

See Participants and Methods on next page 


\section{PARTICIPANTS AND METHODS}

\section{METHODS}

The University of North Carolina has had a required thirdyear family medicine clerkship since 1991. Students are assigned to 1 of 6 Area Health Education Centers (AHECs) across the state. Each AHEC family medicine clerkship director then assigns students to a community preceptor's office for the 4-week rotation. Students see patients for 4 days each week, with side trips to extended care facilities, the local hospital, and patients' homes. The fifth day is spent in seminars held at the local AHEC or the medical school. Midrotation reports generated from student documentation of patient encounters are provided to the preceptor and student, and compare the students' actual exposure with the list of 20 diagnostic groups that form the core clerkship curriculum. Preceptors give the student feedback at a midrotation meeting, at the conclusion of the rotation, and recommend a grade to the clerkship director. If "Honors" is recommended, a letter from the preceptor documenting exemplary performance is required.

\section{STUDY DESIGN}

A qualitative research design was selected because the primary aim of the study was to understand how family physicians viewed their teaching experience in a family medicine clerkship. Questions were developed based on a literature review, discussions with former preceptors, and consultation with current AHEC clerkship faculty. A 15- minute, semistructured telephone interview, composed of closed and open-ended questions, explored 3 areas: preceptors' overall satisfaction with teaching in the clerkship, perceived effect of having students in the practice, and concerns about continuing as a preceptor.

Forty-two private practices composed the original study population. A "primary" preceptor from each practice was identified for the interview. A primary preceptor was defined as the physician responsible for a clerkship student at the practice. In group practices in which several students were placed during the year, physicians often rotated the responsibility of primary preceptor. When this occurred, 1 physician was randomly selected as the respondent for the practice. The AHEC clerkship directors notified physicians of the survey and requested their cooperation. Anonymity was ensured by the use of 2 trained interviewers not affiliated with the clerkship program (P.Y.F. and M.S.).

Two preceptors were no longer with their practices, and interviewers were unable to contact 2 additional preceptors during the study time frame. Thus, 38 practices were eligible for the interview. Interviewers scheduled appointments with 35 of the 38 primary preceptors, a response rate of $92 \%$. Staff from $3(8 \%)$ of the preceptors' offices declined because the physician does not participate in any surveys.

Responses were entered into $\mathrm{CI} 2$, a computerinterviewing system that allowed on-line data entry during the telephone interview. ${ }^{7}$ Descriptive data were imported from CI2 to a $\mathrm{PC}-\mathrm{SA} \mathrm{S}^{8}$ data set for demographic analysis. Preceptor comments were transferred to WordPerfect $5.2^{9}$ for content analysis, which was independently performed by the researchers, using the testcoding method proposed by Miles and Huberman. ${ }^{10}$ private physicians so that they can teach. A study by Langlois ${ }^{6}$ points to the need for support that is tailored to the size and location of the practice.

Yet, insufficient information exists on physicians' satisfaction with their role as preceptor. Medical schools seeking teachers and community physicians who are considering a teaching role are forced to make decisions about their involvement that often are based on intuition rather than data from physicians who have actually precepted and who can relate their experience. This study attempts to narrow this gap by examining communitybased preceptors' overall views of teaching in a clerkship, perceived effect of student teaching on the practice, and concerns about continuing as a preceptor.

\section{RESUI.TS}

Of the 35 participating primary preceptors, 33 (94\%) were actually interviewed. Two solo practitioners missed scheduled interviews because of emergencies in their practices, and subsequent attempts to reschedule were unsuccessful. Of the 33 primary preceptors interviewed, 22 $(67 \%)$ were men, $13(39 \%)$ were in solo practices, and $20(61 \%)$ were in rural locations. These primary preceptors averaged 15 years since completion of medical school, and $17(52 \%)$ of the practices had precepted students 5 years or less. Twenty-four (73\%) of the 33 preceptors had precepted more than 1 student during the previous year.
All offices provided full-service family practice, with the exception of obstetrics, which was offered by only a few.

\section{PHYSICIANS' OVERALL SATISFACTION WITH PRECEPTING}

The Table gives preceptors' satisfaction with teaching in the clerkship. Dissatisfaction stemmed from inappropriate conduct on the part of a medical student $(n=1)$ and longer work hours necessitated by a heavy patient workload coupled with the additional time needed to teach students $(n=2)$. Eighteen $(62 \%)$ of the 29 preceptors who indicated a positive teaching experience also mentioned that a student slowed down the practice; however, they believed that the benefits of having a student outweighed the costs. One preceptor summarized the teaching experience: "The experience was positive for me because of the opportunity to teach, rewards of sharing knowledge and things that I do with students." Another commented, "I enjoy interacting with students because it keeps us on our toes. It makes me ... read and keep one step ahead." Another related, "It decreases my isolation since I am a solo practitioner and forces me to be prepared."

Other preceptors reported satisfaction in teaching students specifically about family medicine. "One of the joys of family medicine is passing on the knowledge of family medicine. Thank God for preceptors I had." "I enjoy teaching ... and love sharing that vision [of family medicine] with students." "The reason I'm doing it is the 
feeling of teaching someone and shaping their desire to be a family practitioner ...."

Physicians not only reported satisfaction with their precepting experience but also said that the local clerkship faculty and staff were supportive of their efforts. Thirty (91\%) of the 33 primary preceptors related that their local clerkship administration (AHEC clerkship director, teaching faculty, and staff) was supportive, and 26 (79\%) reported that they received direct, useful feedback from the AHEC clerkship directors after each student rotation.

\section{EFFECT OF HAVING A STUDENT} IN THE PRACTICE

When asked about the effect students had on their practice, $18(55 \%)$ of the preceptors focused their comments on the issue of time management. Eight $(25 \%)$ reported that having a student slowed down the practice. That is, fewer patients were seen or days were extended to accommodate the same number of patients. Five preceptors $(15 \%)$ specifically noted longer hours. Another $5(15 \%)$ reported that they believed they did not have enough time to spend with the student. The most extreme response was described by a solo practitioner: "I arrived 1 hour early to plan the day's activities and stayed an hour late to discuss the day's learning with the student. My office staff was worried about my long hours. I also took work home and stayed up 'til midnight or later. It decreased my patient load by at least $10 \%$ because I deliberately scheduled extra time for patients in order to try to incorporate the student into the practice." Nevertheless, the preceptors quickly pointed out that the time demands were "worth it."

Benefits received were not necessarily tangible, although all preceptors were offered faculty appointments. Twentynine ( $88 \%$ ) of the 33 preceptors reported receiving 1 or more of the following: a faculty appointment, a small stipend, preceptor workshops with continuing medical education credits, preceptor appreciation dinners, textbooks, and certificates and letters of appreciation. Four preceptors (12\%) reported that they had not received any tangible benefit from teaching, including 2 preceptors whose practices had received monetary remuneration. All preceptors mentioned intangible benefits such as the stimulation of having students in the practice, patients' pride that their physician was teaching university medical students, collegial relationships with students, and the sheer enjoyment of teaching.

\section{CONCERNS ABOUT CONTINUING TO PRECEPT}

Physicians were candid in reporting their concerns. Issues included anxiety about poor student-preceptor match, lack of comfort with evaluating and giving feedback to students, management of the occasional problem student, lack of resources for teaching in the office, and loss of revenue to the practice.

\section{Student-Preceptor Match}

Although preceptors received student profiles before their rotation, they occasionally requested that the university provide additional information before the rotation about

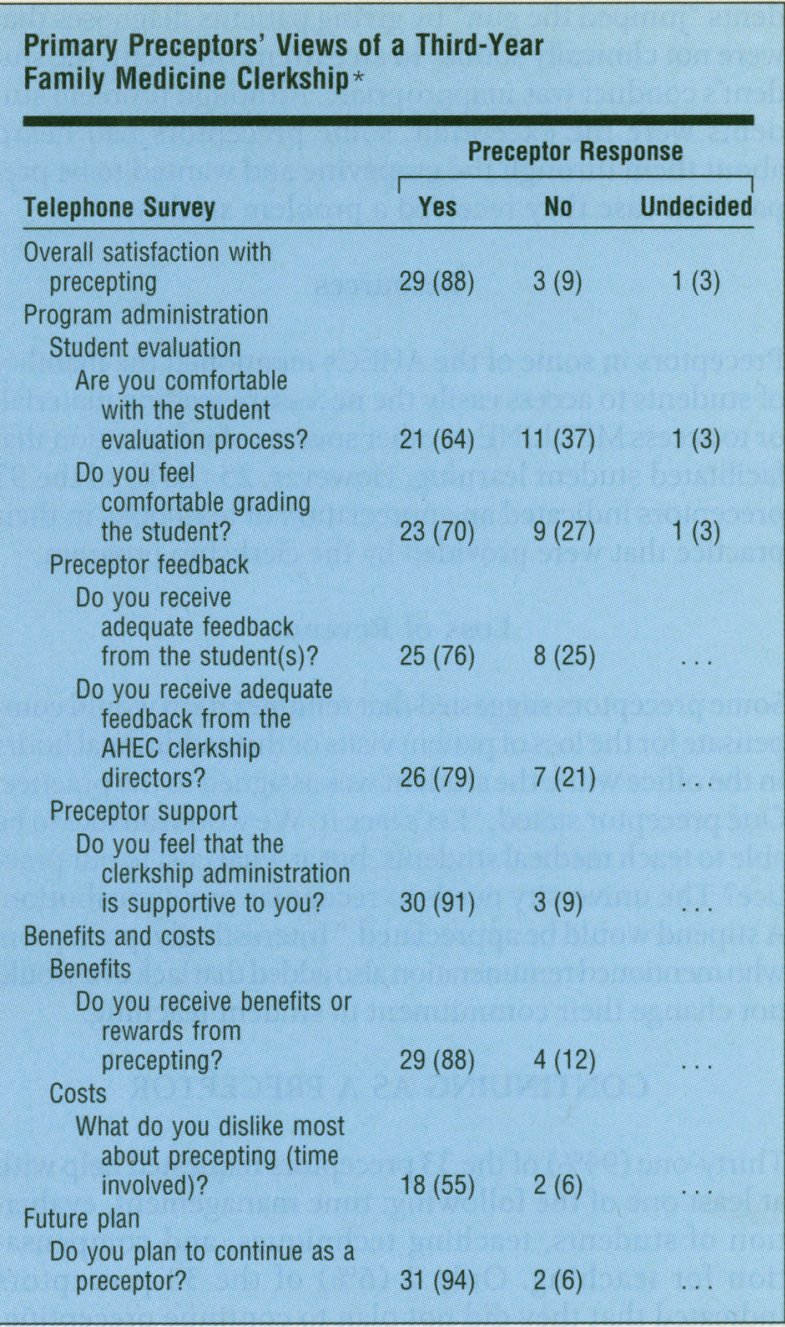

* Values are given as number (percentage) of respondents. AHEC indicates Area Health Education Centers.

student interests, previous experiences, competencies, and areas of special concern. One preceptor stated, "I worry about the match. What if the student and I do not get along?" Another suggested a possible student visit and orientation to the site before the rotation.

\section{Student Assessment}

The major preceptor concern focused on giving feedback to students about their performance and evaluation of students and the subsequent grade assignment. About one third of the preceptors reported that they did not feel comfortable evaluating the student. As a result, one preceptor offered a solution for the group: "Why not make this rotation pass-fail? All of us [preceptors] are concerned that some are 'easy' and some of us have unrealistic expectations. An 'Honors' in one practice may be a 'Pass' in another."

\section{Problem Students}

Two preceptors were concerned about management of problem students. For example, both reported that when feedback was given, the students were argumentative. Another preceptor gave examples of incidents in which stu- 
dents "jumped the gun" by giving patients diagnoses that were not clinically sound. In an extreme incident, the student's conduct was inappropriate. Although problem students were the exception, some preceptors had heard about them through the grapevine and wanted to be prepared in case they received a problem student.

\section{Resources}

Preceptors in some of the AHECs mentioned the inability of students to access easily the necessary reading material, or to access MEDLINE or other sources of information that

- facilitated student learning. However, 25 (76\%) of the 33 preceptors indicated an appreciation of textbooks in their practice that were provided by the clerkship program.

\section{Loss of Revenue}

Some preceptors suggested that remuneration would compensate for the loss of patient visits or their additional hours in the office while the student was assigned to the practice. One preceptor stated, "Let's face it. We would all like to be able to teach medical students, but at what cost to our practice? The university needs to recognize our contribution. A stipend would be appreciated." Interestingly, preceptors who mentioned remuneration also added that lack of it would not change their commitment to student teaching.

\section{CONTINUING AS A PRECEPTOR}

Thirty-one (94\%) of the 33 preceptors requested help with at least one of the following: time management, evaluation of students, teaching techniques, and compensation for teaching. Only $2(6 \%)$ of the 33 preceptors indicated that they did not plan to continue precepting. One, a primary preceptor in a group family practice of 4 , decided to precept students from his medical school alma mater rather than the University of North Carolina. The second, a solo practitioner, opted not to continue because her heavy patient load precluded her from precepting students the way she wanted.

\section{COMMENT}

Although family physicians seem to be satisfied with their experiences as preceptors, many of them did not fully understand the student evaluation and grading system and did not feel comfortable giving students performance feedback. More faculty development may be required, especially for practices that precept only 1 or 2 students each year. Preceptors also expressed concern about time management and loss of revenue. These concerns are supported by previous research.$^{1-3}$ Although material benefits such as books, letters of appreciation, certificates of appreciation, and stipends seem to be appreciated by private physicians, most indicated that the intangible rewards were also valuable.

Based partially on the findings from this study, the North Carolina state legislature appropriated monies to pay modest stipends to all community physicians for medical student precepting. In addition, some of the more active teaching practices have also received computers to facilitate student access to the latest medical information.
A stipend or a computer, however, cannot meet all of the needs of a diverse preceptor population. For example, some preceptors indicated a need for further training in teaching techniques and in evaluating student performance. Others requested assistance with time management, so that they could maintain a full patient load while teaching students in an active solo practice. A recent study by Langlois ${ }^{6}$ reinforces this observation and suggests addressing preceptors' needs based on the unique needs and characteristics of the practice.

Our study was limited to the clerkship of a single school. Nevertheless, the diversity of practice type, practice location, and range of duration of preceptors' teaching experience tend to make this study generalizable to clerkship programs in other schools.

Physicians teaching in a clerkship should be asked about their needs, and special programs of support should be offered. Furthermore, preceptors' needs should be solicited, prioritized, and translated into activities that enhance and support their efforts to teach medical students. In the meantime, findings from this study strongly support the perception that precepting medical students in an intensive clerkship is a satisfying and sustainable experience for family physicians in community practice.

Accepted for publication March 4, 1995.

This study was supported by grant 5 D15 PE84003 from the Division of Medicine of the Health Resources and Services Administration, Bureau of Health Professions. Its contents are solely the responsibility of the authors and do not necessarily represent the views of the Health Resources and Services Administration, Bethesda, Md.

We acknowledge the assistance of Jose Sandoval, MSc, and Beverly Wiggins, PhD, Institute for Research in Social Science, at the University of North Carolina at Chapel Hill, for their consultation with the telephone survey design and data analysis. We also thank Allen Smith, PhD, Office of Education Development, School of Medicine, University of North Carolina at Chapel Hill, for his direction of the graduate student project team in the development and implementation of the study.

Corresponding author: Pamela York Frasier, MSPH, Department of Family Medicine, Campus Box 7595, University of North Carolina, Chapel Hill, NC 27599-7595.

\section{REFERENCES}

1. Pawlson $L G$, Watkins $R$, Donaldson $M$. The cost of medical student instruction in the practice setting. J Fam Pract. 1980;10:847-852.

2. Vinson DC, Paden $C$. The effect of teaching medical students on private practitioners' workloads. Acad Med. 1994;69:237-238.

3. Garg ML, Boero JF, Christiansen RG, Booher CG. Primary care teaching physicians' losses of productivity and revenue at three ambulatory-care centers. Acad Med. 1991;66:348-353.

4. Chambliss J. Experiences with community-based medical education: a preceptor's view. N C Med J. 1989;50:683-684.

5. Usatine RP, Hodgson CS, Marshall ET, Whitman DW, Slavin SJ, Wilkes MS Reactions of family medicine community preceptors to teaching medical students. Fam Med. 1995;27:566-570.

6. Langlois JP. Support of community preceptors: what do they need? Fam Med. 1995;27:641-645.

7. Computer Interviewing System 2 (CI2), Version 2.0. 1993. Available from: Sawtooth Software, 1007 Church St, Suite 402, Evanston, IL, 60201.

8. SAS-PC. 1993. Available from: SAS Institute Inc, SAS Campus Dr, Cary, NC 27513.

9. WordPerfect 5.2. Orem, Utah: WordPerfect Corp; 1992.

10. Miles MS, Huberman AM. Qualitative Data Analysis: A Sourcebook of New Methods. Beverly Hills, Calif: Sage Publications Inc; 1984. 